\title{
MULTICHANNEL DISTRIBUTION METER: A VERITABLE SOLUTION IN POWER DISTRIBUTION AND THEFT PREVENTION IN CONGESTED ENVIRONMENTS
}

\author{
G. 0. Uzedhe ${ }^{1, *}$ and G. Ofualagba ${ }^{2}$ \\ 1,2 Dept of Elect. \& Electronics Engr., Fed. Univ. of Petroleum Resources Effurun, Delta State. NiGERIA. \\ Email addresses:10smenawin22@yahoo.com,2swillas_solar@yahoo.com
}

\begin{abstract}
Power theft in partitioned commercial apartments, especially in the form of unpaid bills due to disputes, is a major challenge to revenue recovery in the power sector. This paper presents a multi-channel power distribution metering solution that serves to resolve disputes among users in partitioned apartments, and between the power distribution company and the end users of electricity. Partitioned apartments in commercial buildings particularly in congested environments shares energy supply meters among several users. This often leads to disputes and results to power theft in the form of unpaid bills and meter tampering. This paper described how power from a single supply meter can be adequately shared among a number of users with dispute arbitration. Each user's channel is fed, monitored and controlled from a central unit which calculate and display energy usage, per unit cost and amount in cash consumed per channel. Compliant/non-compliant channel are connected/disconnected through a remote wireless access. It is envisaged that the use of this method for electricity distribution in commercial apartments, will greatly reduce power theft and increase revenue generation for the power industry. It will also eliminate disputes and possible litigations for the power industry and among users.
\end{abstract}

Keywords: Apartments, Power Theft, Multi-channel, Microcomputers, Distribution

\section{INTRODUCTION}

Quality power distribution at the present is a major challenge in many locations in most developing countries [1]. This is as a result of many factors which range from difficulties of how distribution wires would be laid due to unplanned settlements, building congestion, etc, to multi-apartment buildings. A most distressing part of this power distribution system is the number and manner in which consumption meters are to be installed in multi-apartment buildings. Usually, commercial home owners preferred the installation of one or few number of meters in these buildings resulting to a number of apartments connecting to a single Power Meter (PM). The resultant effect of this is the constant arguments and disputes that ensue among the users of these meters on how the electric bills are to be paid. What formula could be employed to account for the total money is usually a serious problem. This arises from the fact that each apartment has varying load capacity with different consumption behaviour. This behaviour is not constant but changes in an undetermined pattern. In situations where residential apartments are attached to commercial stores, the disputes can be very difficult to resolve as both kind of users blame each other for the rise in the total amount in the bill. Business users could be heavily loaded and consume power in the active time of the day, while residential users mostly draw power only in the early and late active hours of the day. Hence, it is very difficult to apply a fixed-amount billing system for each apartment attached to the meter.

Several such buildings with accumulated and abandoned bills are in the records of the power distribution companies. This is one of the most prevalent forms of electric power theft that is difficult to account for [2], [3]. Unfortunately, the only possible action that could be taken and seem effective on the side of the distribution companies is outright disconnection of such buildings from the grid. 
However, it is not of good advantage to the company since there will be less consumption leading to low return on investment. Outright disconnection in most partitioned apartment buildings also lead to other forms of theft particularly meter tampering and bypass connection. Hence a solution must be sought to resolve this anomaly to satisfy both the apartment dwellers and the power distribution company.

Crudely, fixed-amount charge processes that will produce the total amount have always been applied. This is very disadvantageous to low power consumers as it only transfer expenses of others to them. This usually lead to load increment as aggrieved users resort to the addition of more, probably unwanted, loads in order to compensate for their payment. The final possible result is overloading and breakdown of the installation components. In this paper, a veritable multi-channel distribution power meter (MDPM) solution is presented as a reliable solution for multiapartment electricity users as well as the power distribution company. Since the modern digital microcomputers (microcontrollers) are becoming very handy in the form of integrated circuits (ICs) with increasing computational power, memory capacity, and peripheral additions, the microcontroller quickly fit into such areas of complexity simplification. Already, the analogue meters are gradually being replaced by their digital counterparts, which come with the capability of automatic disconnection. Yet, in every other way are reminiscent of the analogue ones in areas of multi-user distribution outlets as they come with a single output channel and display purposely made for a single user.

\section{REVIEW OF METERING SOLUTIONS TO ELECTRIC POWER DISTRIBUTION AND THEFT IN COMMERCIAL APARTMENTS}

Over the years, there have been several ways electrical power is unlawfully used by industries, commercial business owners, home owners, and apartment tenants [4]. This is power theft and has serious effect on power generation, transmission and distribution [5] due to possible overloading that leads to power equipment breakdown. It also results to loss of revenue by the distribution companies as well as possible over billing of legal consumers.

Industrial and commercial business power thefts are less common but could be significant when carried out and are quite easier to trace. The larger percentage $(80 \%)$ of power theft is from home owners and apartment tenants [4]. Cases with single family occupied homes are very easy to solve by total isolation from the distribution point. This however, is not the case with multi-apartment homes where all apartments are feed with a single distribution wire. Distribution companies have tried to isolate these apartments power usage by the provision of separate utility meters. This have only serve the sole purpose of separating bills for fast revenue recovery. The aftermath of the use of separate meters in these multiapartment homes is the possible increase of other means of electrical power theft which occurs in the form of meter tampering and bypass.

Another type of tenanted apartment prevalent in several cities of most developing countries is partitioned apartments. These apartments share several utilities together including energy meters. Payment of electric utility bills in these type of apartments are usually very difficult and will always result to theft in the form of abandoned bills and sometimes, corporate agreement by the users to bypass or tamper with the meter.

Several solutions to combat electrical power theft have been employed over the years [6]. Empirical analysis carried out by [7] shows that a better commitment to the provision of adequate power and proper management through privatization, government price regulation and consumer protection will reduce conflict between providers and users of electricity thereby reducing theft. At the moment, technological solutions are becoming more available. Prepaid and smart meters are being developed and deployed to homes [8], [9] though with some controversies [10].The authors of [11] proposed a model for Intelligent Power Theft Detection System (IPTDS). The model assumes a tree connection system of meters at various levels where by power usage variations can be monitored and illegal loads detected and reported to the utility company. In [2] , [12] and [13], Global System for Mobile communication (GSM) based solution were presented. The authors proposed remote monitoring of meter readings and customer behaviour around the meter in order to track abnormalities and report same to the utility company with possible cutting off of connected loads, as a means of detecting and preventing theft. The authors of [14] presented a theft prevention system by comparing the total power supplied by the distribution transformer and the total load used by the consumers. They envisage the use fuzzy logic controller to gradually reduce supply voltage and eventually cut off supply with respect to error 
detection between supplied and consumed energy. In [3], the authors presented a meter tampering theft detection system for both analogue and digital energy meters. The proposed meters in their work uses current sensing transformers for both the life and neutral lines to detect pilferages in digital meters, while a light emitting diode (LED), a light dependent resistor (LDR), and a partially shaded aluminium disc are used to detect tampering in the analogue meters. Both systems employed the microcontroller for measurement and comparison of voltage or current changes in the meters to report theft.

\section{THE POWER DISTRIBUTION SOLUTION}

In order to militate against these disputes, a self dispute resolution microcomputer based solution is proposed in this paper. The computer is generally known to be multi-functional [15] and can be applied in this scenario to adequately and proportionally distribute energy consumption [16] among users occupying different apartments in a building connected with a single point Power Meter (PM). Here, the computer is made to act as a distribution point expander and a cost accumulator.

Let the total load connected to PM be given by

$Z=z_{1}+z_{2}+z_{3}+\ldots \ldots z_{N-1}+z_{N}$

Each of these loads will draw its own specified amount of electrical current that is proportional to its size, which will add up to produce total power demand on the single supply meter given by $P$.

Then,

$P=P_{1}+P_{2}+P_{3} \ldots \ldots \ldots P_{N-1}+P_{N}$

But $P=I^{2} Z$ where $I$ is the total current drawn and $Z$ is apartments total load. Therefore,

$$
\begin{aligned}
P=i_{1}^{2} Z_{1}+i_{2}^{2} Z_{2} & +i_{3}^{2} Z_{3}+\ldots \ldots \ldots .+i_{N-1}^{2} Z_{N-1}+i_{N}^{2} Z_{N} \\
& =\sum_{1}^{N} i_{N}^{2} Z_{N}
\end{aligned}
$$

Hence, for any apartment, power drawn from the supply meter $\left(P_{N}=i_{N}^{2} Z_{N}\right)$ is function of the load applied to that apartment. This load cannot be subjected to continuous measurement since it is constant and can only be changed by the user. From ohm's law we have that

$$
v=i z
$$

This produces a parameter voltage (v) that can be subjected to continuous measurement. This voltage is however the same for all users. That is,

$$
i_{1} Z_{1}=i_{2} Z_{2}=i_{3} Z_{3}=\ldots \ldots \ldots=i_{N} Z_{N}
$$

Substituting equation (5) into equation (3) we have

$$
\begin{gathered}
P=i_{1} v+i_{2} v+i_{3} v+\ldots \ldots \ldots \ldots+i_{N-1} v+i_{N} v(6) \\
P=v\left(i_{1}+i_{1}+i_{3}+\ldots \ldots \ldots \ldots i_{N-1}+i_{N}\right)
\end{gathered}
$$

From equation (7), we found that power demanded at any time by any apartment is a function of the supply voltage and current drawn by the apartment load. Therefore, measuring the supply voltage and the current drawn by each apartment over time, energy $\left(e_{N}\right)$ consumption at each apartment can be computed as:

$$
e_{N}=P_{N} t=i_{N} v t
$$

Since current drawn is not constant but varies with load capacity and time, the energy could be best calculated and accumulated using:

$$
e_{N}=\int_{t_{1}}^{t_{2}} i_{N} v t d t=v \int_{t_{1}}^{t_{2}} i_{N} t d t
$$

If the unit cost (c) of energy consumed is determined, then amount $(\mathrm{A})$ payable by the apartment user is:

$A=v c \int_{t_{1}}^{t_{2}} i_{N} t d t$

Applying the computing power of the modern day microcomputer (microcontroller) combined with its high speed; these values can be accurately and precisely computed. With its high speed and multiple input/output pins, the microcontrollers can switch through a number of consumption points with the ability to handle connect/disconnection functions, display functions, and communication functions as required.

\section{METER DESIGN}

Figure 1 depicts equation (6), the power measured by the energy supply meter is the total sum power consumed from all connected users. Hence, the power distribution metering system must measure each channel's power consumption accurately in order to calculate its energy usage over time and determine the amount in cash accrued to that channel.

Figure 2 is a detail internal configuration of the metering system. Basically, the system consists of a switching unit, a sensing unit, a measurement and control unit, and communication unit. The switching unit ensures that the incoming power is passed to each channel through individual electronic switches. This enables the control system to measure consumptions as well as carryout on/off switching operations per channel. Hence, connect and disconnect functions are easily handled without effect on compliant channels. 


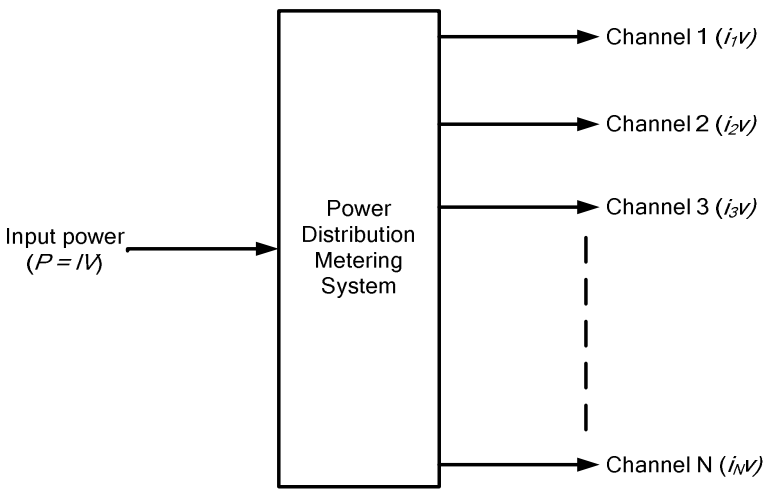

Figure 1: Block Diagram Representation of the Metering System

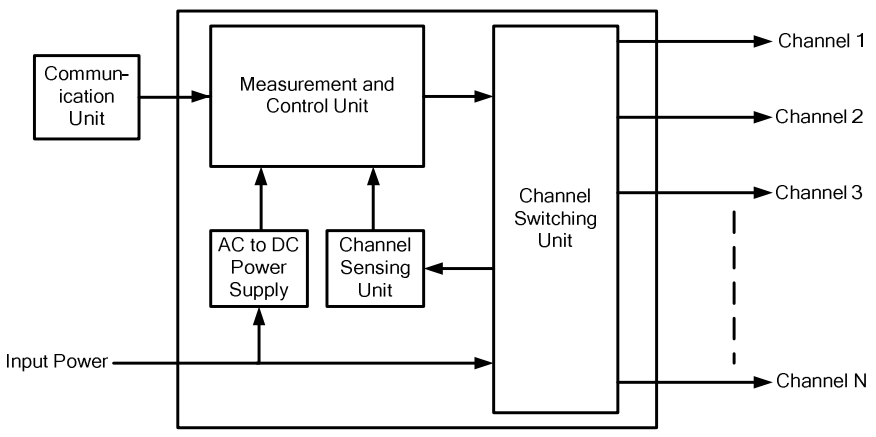

Figure 2: Simplified Block Representation of the Metering System

The sensing unit picks up current and voltage signals from each channel for measurement by the control unit. The measurement and control unit acts as the brain of the meter and carry out all operations as defined by the system algorithm. Finally, the communication unit serves as the human-machine interface which enables users to communicate and effect changes in the system.

\subsection{The Channel Switching Unit}

The channel switching unit is a separator that isolates each channel from the main supply. A channel is only connected to the source via an electronic switch through a command from the control unit. There are several available electronic switches that could serve this purpose. In this case, however, the solid state relay with inbuilt opto-isolator is recommended. As shown in Figure 3, the solid state relay enables the separation of the small control DC voltages from the large mains $\mathrm{AC}$ voltages. Because these relays isolate each channel from the mains source, individual channel consumption can easily be measured, monitored and controlled. Therefore, each user can only be billed for what is consumed over time. Based on the command received, specified channel(s) could be monitored and controlled ON/OFF to connect or disconnect a user

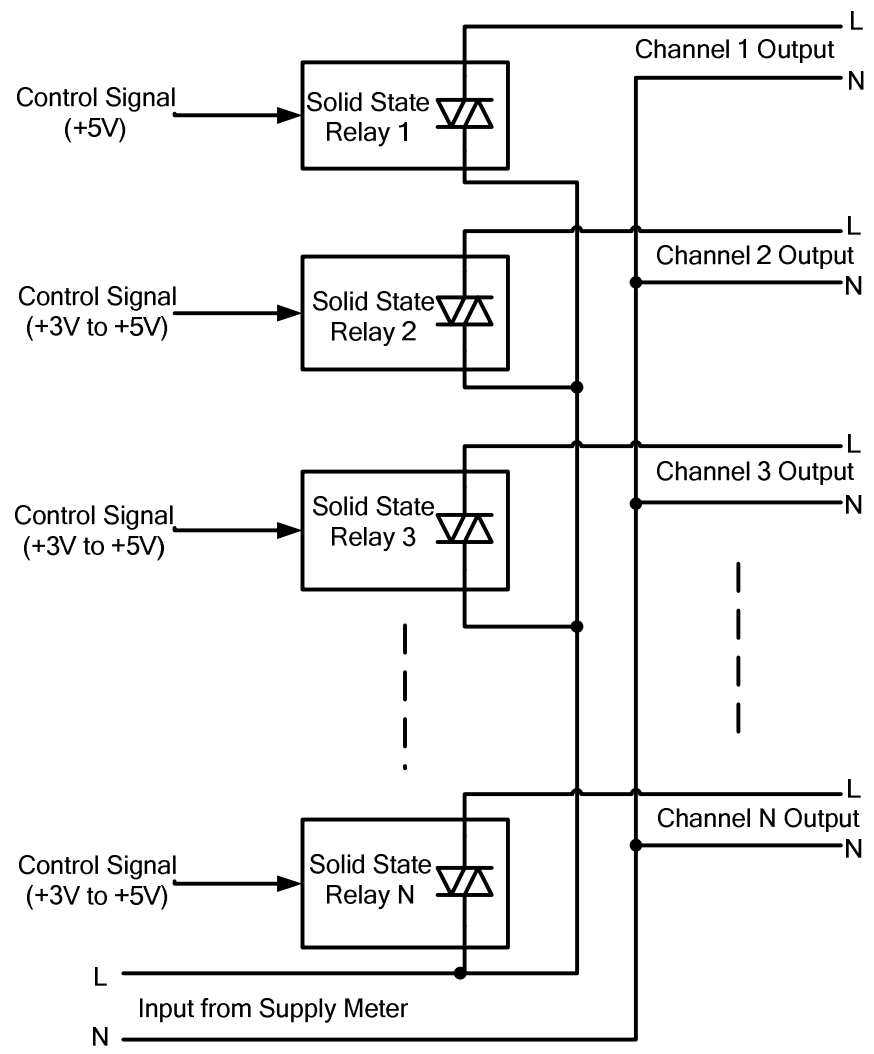

Figure 3: The Switching Unit Design

\subsection{Sensing Unit}

The sensing unit consists of a single voltage sensor and $N$ number of current sensors. As shown in Figure 4 , these sensors are usually in the form of voltage and current transformers attached to signal conditioners. The voltage transformer steps down the large AC voltages to their small AC equivalents voltages, while the current transformer converts the current drawn from each channel to its small AC voltage equivalent. Both of these small equivalent voltages are passed through signal conditioning units which convert these AC signals to their DC equivalent. The DC analogue equivalent of the voltage and current signals are further fed to the measurement and control units for onward manipulations.

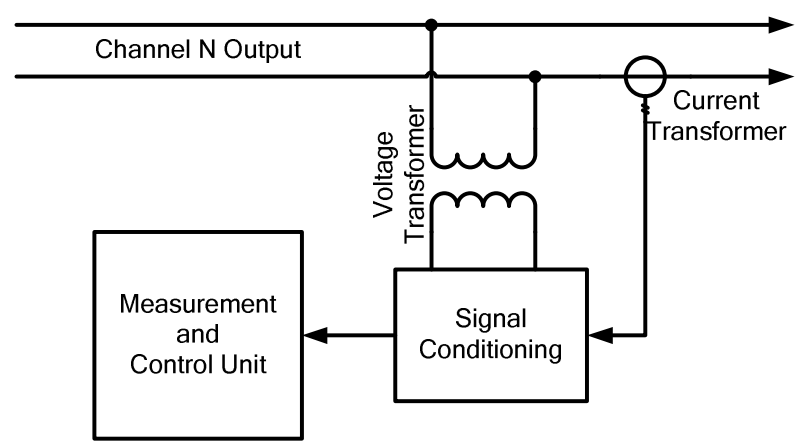

Figure 4: The Sensing Unit Design 


\subsection{Measurement and Control Unit}

The measurement and control unit shown in Figure 5, houses a multi-channel analogue to digital converter (ADC), a data processing unit, a signal buffer, and a display unit. The conditioned analogue signals are first converted to their digital equivalent by the ADC on a channel by channel basis using selective time multiplexing.

The ADC can be of any number of bits ( $n$-bits) which determine the resolution of the conversion. Higher number of bits produces better resolution and hence the systems accuracy. However, higher number of bits means more complexity and imposes on the system the need for higher processing power and larger memory requirement. The minimum industrial standard with which good accuracy could be maintained is 10bits. There are lots of microcontrollers in the market at present that implements 10bit and12bit ADC function as a peripheral interface addition that can be used for this purpose.

The converted digital signals are received by the data processing unit. The data processing unit is a microprocessor with volatile and non-volatile memories and other connected peripherals that make up the microcontroller. It holds the operational algorithm for the systems operation. Using the voltage and current data received from the ADC, the processing unit processes and calculate each channels energy usage over time and amount accrued to each. It is also responsible for the display of these variables on the user display interface, receive control inputs, and make decision to connect or disconnect a user by sending the appropriate control signals to affected channels.
A variety of display type can serve the purpose of the display unit. However, the most appropriate for this system is the liquid crystal display (LCD). The LCD comes in various types and gives less design complexity in terms of reduced wiring, reduced programming, and size and aesthetics. The control inputs are received by the processing unit through a wireless device terminal. The wireless terminal can be of any compatible wireless technology with the microcontroller implementing the processing unit. Possible wireless technology includes Radio Frequency (RF), Bluetooth, WiFi, ZigBee, and Infra Red which implements various IEEE standards. Control signals from the processing unit are sent to the channel switches via signal buffer (driver). The buffer functions to isolate the microcontroller from the switches and drive the weak signals from the microcontroller to the required voltage level for the switching operation.

\subsection{Data Entering and Communication Unit}

From time to time, the need to review the energy unit cost on the MDMP (due to changes in tariff from the distribution company on the PM)and issue commands to connect or disconnect non-compliant users, or even isolate specified channel(s) for line fault correction may arise. Therefore, the metering system must be provided with a data entering unit to enable these changes to be made. The most probable data entry component to use for this purpose is an alphanumeric keypad by which key combinations representing some functions can be entered.

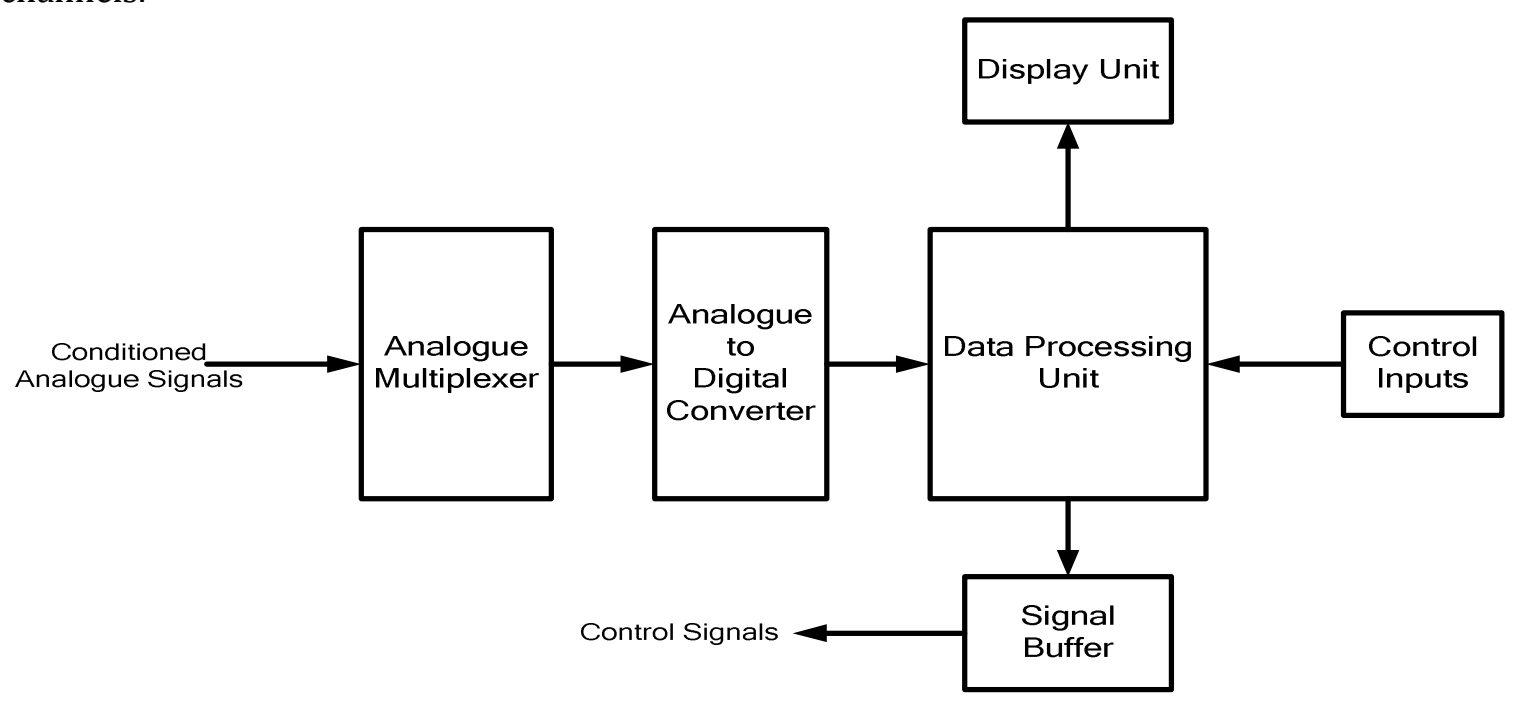

Figure 5: Measurement and control Unit 


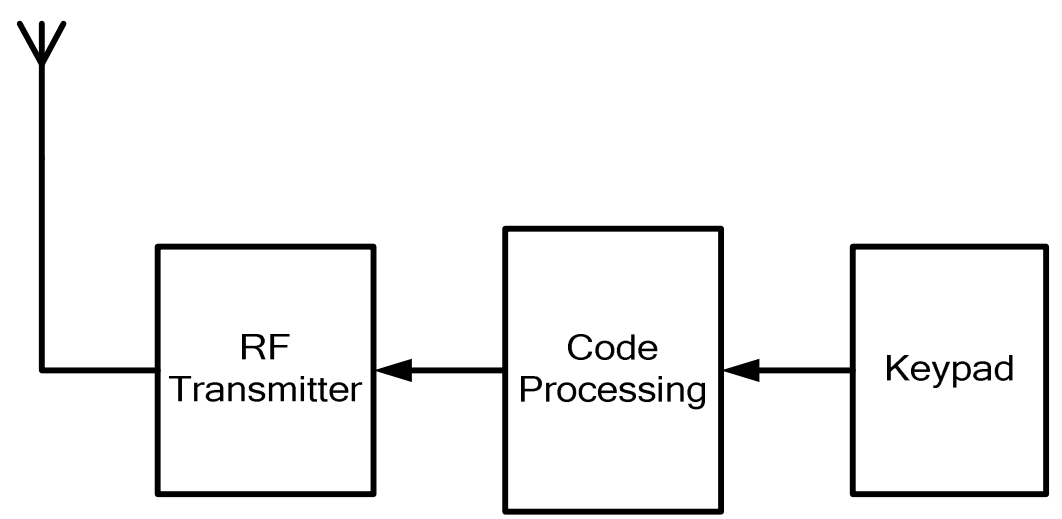

Figure 6: Data Entering Remote Control Unit

However, the meter is required to be install out of easy hand reach or even properly sealed against possible fraud and from being vandalized by defaulters. Hence, the most convenient means to enter these changes is through wireless communication.

The keypad, a code processing circuitry, and a wireless transmitter form a remote control terminal as shown in Figure 6 for data entering into the metering system. Information entered through the keypad are processed and sent to the measurement and control unit through the wireless transmitter.

\section{DISCUSSION}

The proposed meter is meant to prevent possible arguments and their after effects, which result from reactions to collective bill payment through flat rates by users of shared supply energy meters. The supply meter is serviced and charged as a single point by the electricity provider. This will greatly reduce the number of contact points with users, and in conjunction with appropriate installation practice, the magnitude of meter tampering and bypass theft. Of course, the use of the proposed metering system will help to share the responsibility of theft control between providers and users of electricity. Individual users, connected to the supply meter through the proposed distribution meter, are charged and billed independently as though they are not connected to the same supply meter.

Furthermore, the proposed distribution meter can be managed by the home owners, appointed persons, or a third party business outfit. While this creates possible employment opportunities, it reduces over dependence on electricity providers for immediate services.

\section{CONCLUSION}

This paper presented a multi-channel metering solution for power distribution in commercial residents. The method proposed will adequately reduce electricity supply and usage disputes, theft, and over dependence on providers. All these are possible through the separation of end-users from the providers with the proposed meter acting as an arbitrator. The adoption of this system for use, therefore, means that there will be increase in returns on investment for electricity business owners. Endusers will also be satisfied with value for their money.

\section{REFERENCES}

[1] E. C. Chinwuko, C. O. Mgbemena, P. S. Aguh, W. S. Ebhota, "Electricity Generation and Distribution in Nigeria: Technical Issues and Solutions", International Journal of Engineering Science and Technology, Vol.3 No. 11, pp7934-7941, November 2011.

[2] D. O. Dike, U. A. Obiora, E. C. Nwokorie, and B. C. Dike, "Minimizing Household Electricity Theft in Nigeria Using GSM Based Prepaid Meter", American Journal of Engineering Research, Volume-4, Issue-1, pp59-69, January 2015.

[3] S. D. Himadri, Munzur-ul-Mamun, M. Shahadat, A. Ahamed, S. U. Ahamed, and K. S. Arefin, "Design and Implementation of a Novel Protection Device to Prevent Tampering and Electricity Theft in Commercial Energy Meters", JCIT, Volume 01, Issue 0, pp88-94, 2010.

[4] K. A. Seger and D. J. Icove, "Power Theft-The Silent Crime", FBI Law Enforcement Bulletin, March 1988, [online]. Available: http://web.eecs.utk.edu/ PowerTheft [Accessed: 20/02/2015].

[5] M. Golden and B. Min, "Theft and Loss of Electricity in an Indian State", Version 3.0, 2012, [online]. Available: $\quad$ http://www.yale.edu/Leitner/ resources/paper [Accessed: 20/02/2015]. 
[6] B. Saikiran and R. Hariharan, "Review of Methods of Power Theft in Power System", International Journal of Scientific and Engineering Research, Volume 5,Issue 11, pp276-280, November 2014.

[7] K. Subair and D. M. Oke, "Privatization and Trends of Aggregate Consumption of Electricity in Nigeria: An Emperical Analysis", African Journal of Accounting, Economics, Finance and Banking Research, Vol. $3.18-27$, No. 3, 2008.

[8] The Edison Foundation, "Utility-Scale Smart Meter Deployments, Plans, and Proposals", Institute for Electric Efficiency (IEE) Report, 2012, [online]. Available: http://www.edisonfoundation.net [Accessed: 20/02/2015].

[9] S. P. B. Kumer, "Are We Ready for Era of Smart Prepaid Services?" Wipro Council for Industry Research, [online]. Available: http://www.wipro.com [Accessed: 20/02/2015].

[10] B. J. Murrill, E. C. Liu and R. M. Thompson II, "Smart Meter Data: Privacy and Cyber security", Congressional Research Service, 2012, [online]. Available: http://www.crs.gov [Accessed: 20/02/2015]

[11] B. O. Omijeh, G. I. Ighalo and F. I. Anyasi, " Intelligent Power Theft Detection Model for Prepaid Energy Metering in Nigeria", International Journal of
Electronics Communication and Computer Engineering, Volume 3, Issue 6, pp. 1366-1371, 2012.

[12] M. Nabil, B. Anomadashi and A. A. Muhammed, "A Smart Prepaid Energy Metering System to Control Electricity Theft", International Conference on Power, Energy and Control (ICPEC), 2013.

[13] Dr. M. J. C. Prasad and Y. Kiran, "Prepayment of Electricity Units with Theft Controlling System", International Journal of Research Studies in Science, Engineering and Technology, Volume 1, Issue 4, pp. 42-48, July 2014.

[14] S. Rengarajan and S. Loganathan, "Power Theft Prevention and Power Quality Improvement Using Fuzzy Logic", International Journal of Electrical and Electronic Engineering, Vol-1, Iss-3, pp. 106-110, 2012.

[15] F. Tanshi and N. Bello, "A Basic Approach to Designing Embedded Systems using a Simple Calculator and C Programming Language", Nigerian Journal of Technology, Vol. 33. No. 3, July 2014, pp. $359-366$.

[16] C. C. Okeke, "Applications of the Digital Computer in the Improvement of the Socio-Technological Conditions in a Developing Economy", Nigerian Journal of Technology, Vol. 6 No. 1 September 1982. 